\title{
ciênciaenatura
}

\section{Safeguarding energy tunnels against explosive load by using concrete and soil annihilators}

\author{
Mahmood Reza Toloue Hassanpour ${ }^{1}$, Seyed Mojtaba Movahedifar ${ }^{2}$ \\ ${ }^{1}$ M.S. student, Department of Civil Engineering, Khorasan Razavi Science and Research \\ Branch, Islamic Azad University, Neyshabur, Iran; mrt_hassanpour@yahoo.com \\ ${ }^{2}$ Assistant Professor, Department of Civil Engineering, Neyshabur Branch, Islamic Azad \\ University, Neyshabur, Iran; movahedi_far@yahoo.ca
}

\begin{abstract}
Utilization of buried structures is one of the usual approaches of non-factor defense in order to protect vital plants and arteries of cities against terroristic attacks (explosion). Besides the examination of the effect of surface and deep explosions on buried structures and how to model and analyze them in Abaqus software and in $3 D$ mode, this study investigates various strategies to improve their safety. In this investigation, the influence of using concrete annihilators made horizontally on the upper surfaces of tunnels is examined. In addition, the improvement of the performance of these structures by using soft sand vertical sinks that are able to be made around energy tunnels, is examined. Investigations show that although using anti-explosion eagles reduces the damages of explosive loads, using mixed annihilators may effectively improve this performance.
\end{abstract}

Keywords: Buried structure, energy tunnel, explosive load, annihilator, reinforcement 


\section{INTRODUCTION}

It has long passed since the appearance of the explosion technology and the knowledge of explosive loads during which many theoretical and laboratory tests have been performed by engineers and scientists on materials and explosive loads. Today with the unfortunate expansion of terroristic attacks, the analysis and design of explosive-resistant structures has also been extended and various codes have been presented by different researchers for explosive analysis and design. On the other hand, with the appearance of new materials, the extension of their uses in civil engineering and their proper uses in the optimization of the existing structures, a new scope has been provided to fight these events.

Explosive analyses have a long history as long as several centuries. Preliminary analyses by approximate methods date back to $13^{\text {th }}$ and $14^{\text {th }}$ centuries. In1919 the scale law was presented by Hopkinson for simple explosions. It had no mathematical basis, but was very important in terms of placation [2].

He argued that if two buildings with similar shapes and materials, but in different sizes are built and then exploded, the amount of explosives required for making similar effects is directly proportional to the third power of the buildings' sizes. This law was completely introduced by Griz (1926) [4].

Horus Lamb - the mathematician of Manchester University- conducted various researches in hydrodynamics and the waves' distribution phenomenon. Taylor was a scientist whose studies on the dynamics of explosive waves of explosives played a major role in the development of the British Defense Ministry Research Center in 1936-1950. His first papers were about the distribution and annihilation of the explosive waves of common weapons, but in next studies, he focused on the explosive wave behavior as a result of the first atomic explosion in New Mexico [1].
Various researches have shown that malleable materials even with less resistance have a very better performance against explosive loads. One of the studies conducted in this respect is the performance investigation of bridges' decks with different materials against the loads of the vehicle's explosion. In this research, Jean Sun and Astaneh examined the bridges' decks in two modes with steel cans and in composite form. In the former, the behaviors of three different steels and in the latter, the behavior of common highresistance concrete was examined. It is interesting to say that the results indicate that steel or concrete materials with lower resistance and higher flexibility have a far better performance. Another research conducted by Astaneh in this respect is related to the explosive effect of the vehicle on his suggested wall that is mixture of steel and concrete shear walls. It is composed of a steel plate welded to the skeleton on which an eagle made of armed concrete is installed by bolts and nuts. The weakness of common concrete walls is that they are crashed under the influence of explosion and their particles move in the environment with a very high speed. These quivers in turn may cause severe damages and losses. However in this type of wall, the existence of a steel plate behind the wall prevents the concrete particles from flying and indeed resolves this risk [3].

Locioni is another researcher who has conducted various studies on explosion. In one of such researches, the behavior of concrete eagle under the influence the explosive load is examined. First he put a concrete eagle under the influence of an explosive load in laboratory and then compared the results by modeling by Abaqus and Ansys software. After showing the modeling accuracy, he tried to establish a relationship between the explosive hole's diameter, the explosives weight and the location of explosion. Finally he performed a comparison between the models and 
software used and explained the weaknesses and strengths in each case [5].

Also Foyooz et. Al. examined the behavior of steel and concrete structures with different shapes and conditions under the influence of explosive loading. They simulated and compared the influence of shape and other features on the structure's performance for both steel and concrete by finite difference software, i.e. Abaqus and reported that the performance of concrete structures is generally more suitable [6].

\section{NUMERICAL MODEL}

This numerical model considers a 5x10-m rectangular energy tunnel model by finite difference software, i.e. Abaqus. Its thickness is $50-\mathrm{cm}$ made of C40-grade concrete. In this numerical model, upper concrete eagles are used in order to annihilate the explosive force made of C50grade concrete are placed on the upper part of the structure on 1,2 and 3-m heights under the eagle's ceiling. These annihilators are $7 \times 10 \times 12-\mathrm{m}$ with $80-\mathrm{cm}$ thickness. In addition, regular-distance sinks are made around the tunnel's structure the inside of which is filled with soft sand. They are 50$\mathrm{cm} \mathrm{D}$ and 10-m H located at 3.6-m distances from each other. Sinks play the role of annihilators to protect the structure's body. in order that the structure has a better performance in the depth of Earth, the perimeter is filled with sand, since sand not only can play the role of an annihilator, but also may discharge the water around the structure. Figure 1 shows a schematic of the numerical model.
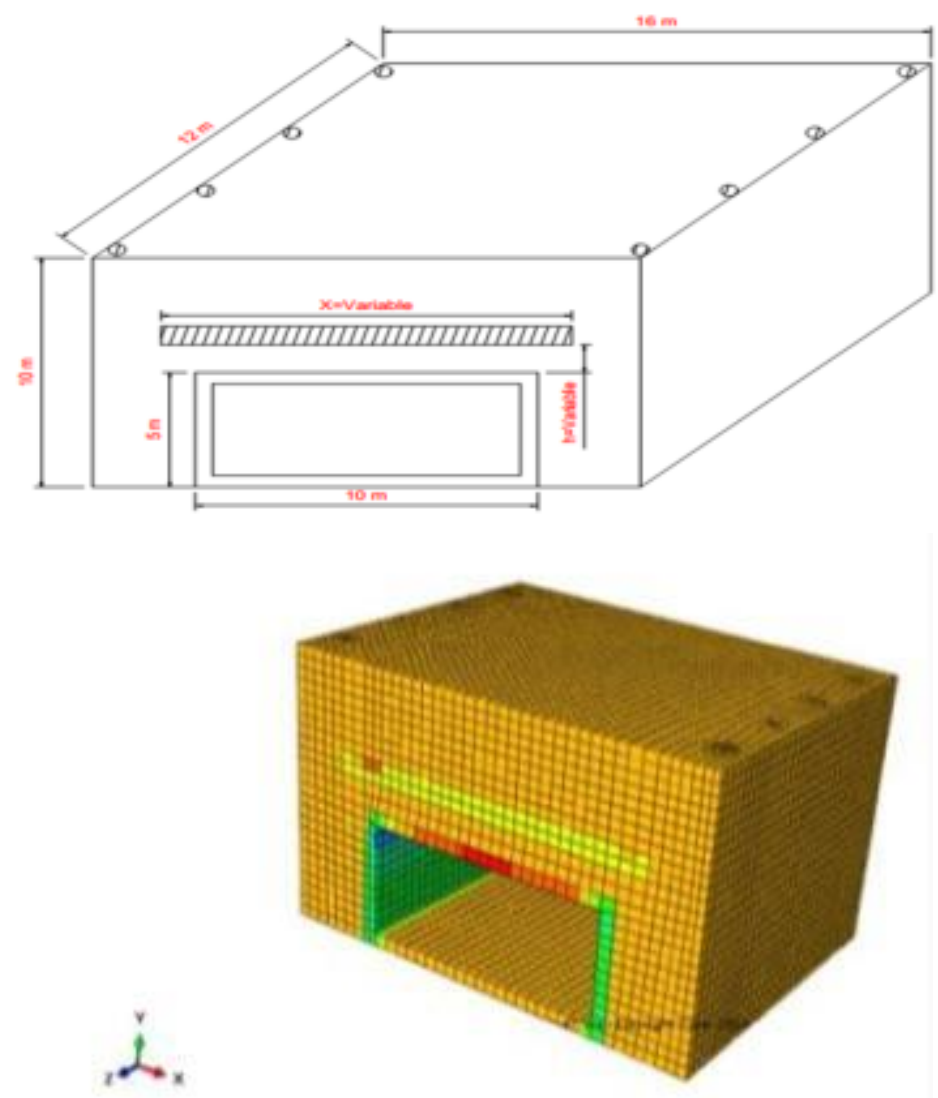

Fig. 1. Schematic of the numerical model and the dimensions

In addition, table 1 explains the specifications of the consumed materials.

Table 1. Materials' specifications 


\begin{tabular}{cccccccccc}
\hline Specifications & Density & $\begin{array}{c}\text { Young's } \\
\text { modulus } \\
\mathrm{MPa}\end{array}$ & $\begin{array}{c}\text { Poisson's ratio } \\
\mathrm{Kg} / \mathrm{m} 3\end{array}$ & $\boldsymbol{\beta}$ & $\begin{array}{c}\text { Angle of } \\
\text { friction } \\
(-)\end{array}$ & $\begin{array}{c}\text { Dilation } \\
\text { angle } \\
(\mathrm{o})\end{array}$ & $\begin{array}{c}\text { Strain } \\
(-)\end{array}$ & $\begin{array}{c}\text { Adherence } \\
(-)\end{array}$ \\
\hline C40 Concrete & 2423 & $2957254 \times 10^{6}$ & 0.2 & 0.00233 & - & 30 & 0.001 & - \\
C50 Concrete & 2423 & $2957254 \times 10^{6}$ & 0.2 & 0.00233 & - & 30 & 0.001 & - \\
Soft Sand & 1600 & $3744 \times 10^{6}$ & 0.3 & 0.3 & 30 & 0 & 0.2 & 0.001 \\
Sand & 2200 & $1 \times 10^{8}$ & 0.3 & 0.3 & 40 & 0 & 0 & 0.001 \\
Steel & - & $21 \times 10^{10}$ & 0.3 & - & - & - & - & - \\
\hline
\end{tabular}

Explosive loading depends on both time and location parameters. This research ignores loading dependence in order to simplify and decrease the operational time required for the models computer simulation. It only refers to the load time distribution. In other words, the pressure Committee (AISC). In this study, the applied pressure is considered equal to the pressure as a result of the explosion of 9.5 $\mathrm{kg}$ TNT at the distance of $2.5 \mathrm{~m}$ away from the structure. Pressure is applied to the distribution as a result of explosion is applied to the surface in the form of a uniform, but time-dependant pressure. This may be known acceptable with reference to the explosion code of the American Steel Structures

Manufacturing

structure during the whole period of $0.02 \mathrm{~s}$ in the form of a trapezoid. Figure 2 shows the history of the loading applied to the structure.

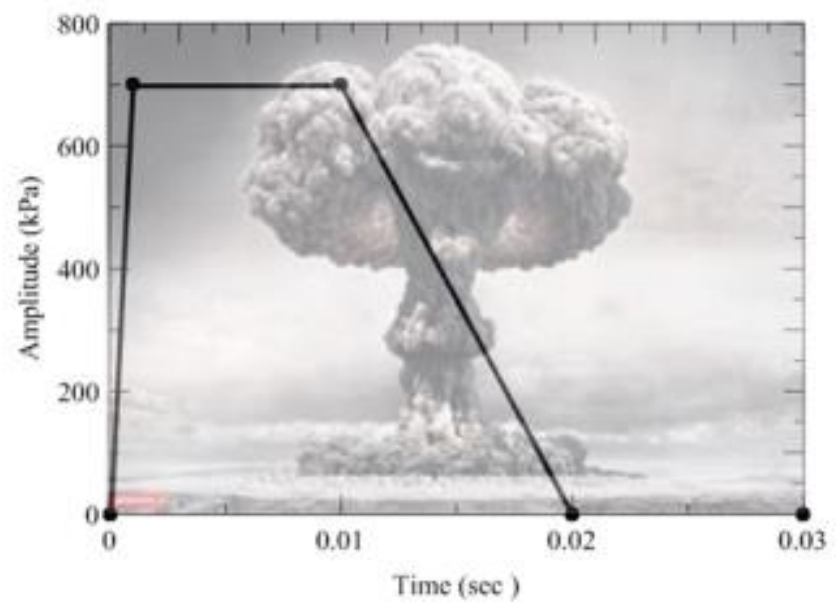

Figure 2. The history of the explosive loading

Below we examine the results of the numerical mode analysis.

\section{3- RESULTS ANAYSIS}

In this analysis, both parameters of the annihilator's length and its upper eagle's height are examined to obtain 9 modes for the maximum stress and displacement with vertical annihilator and 9 modes without it.
3.1. In this mode, the length of the upper annihilator is $7 \mathrm{~m}$ and its height up to the tunnel's ceiling is considered in three cases, i.e. 1,2 and $3 \mathrm{~m}$. the results are shown in figures 3-4 in order to be compared to cases 1-2 shown with vertical annihilators. 


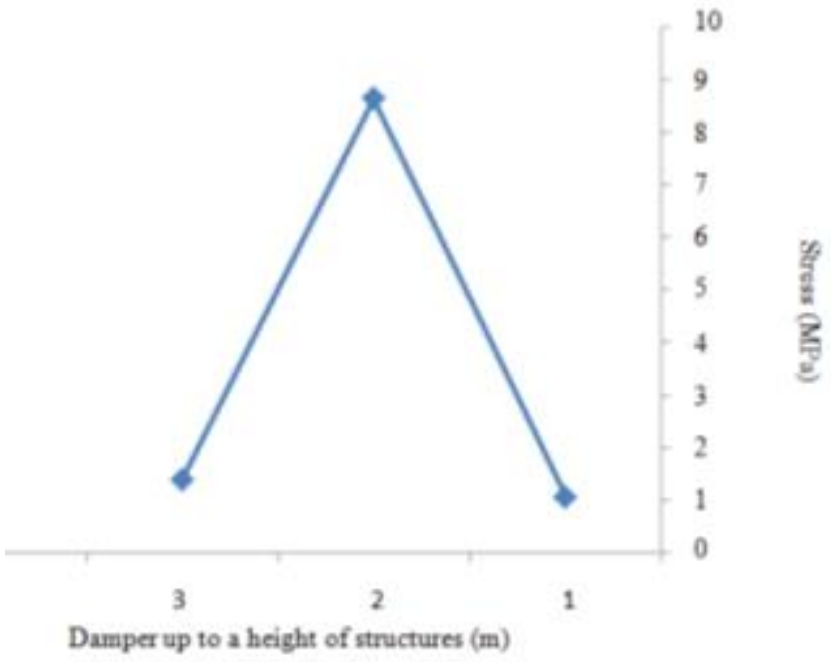

Fig. 1. maximum stress for the 7-m horizontal annihilator with vertical annihilators

3

2

1

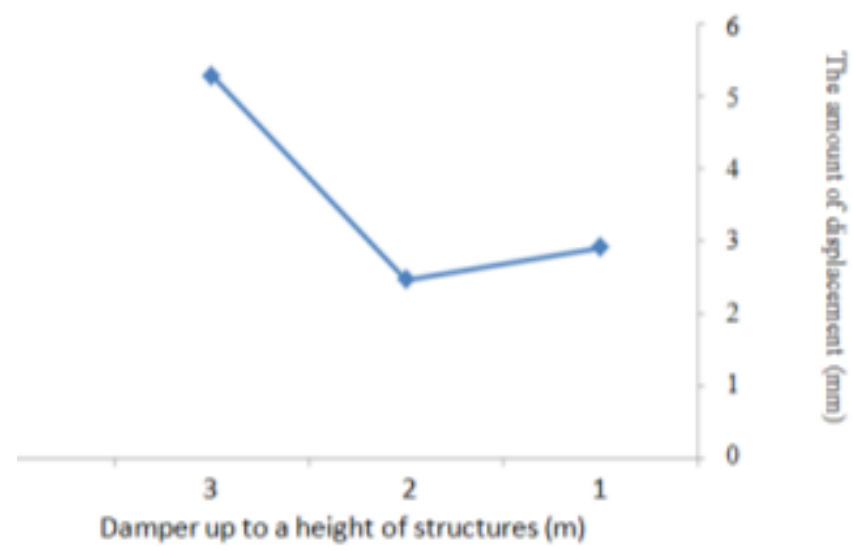

Fig. 2. maximum displacement for the 7-m horizontal annihilator with vertical annihilators

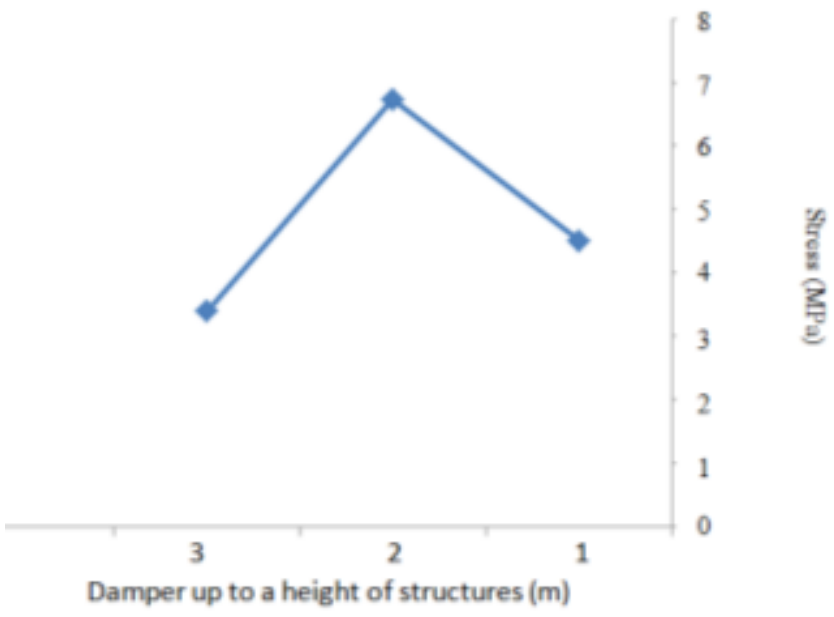

Fig. 3. maximum stress for the 7-m horizontal annihilator without vertical annihilators 


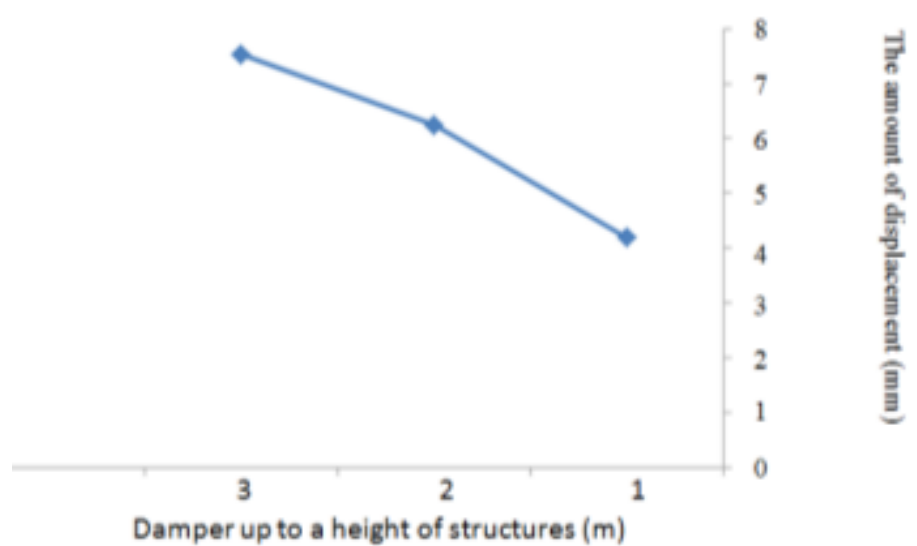

Fig. 4. maximum displacement for the 7-m horizontal annihilator without vertical annihilators

The above figures show that if the upper annihilator does not protect the whole structure's surface, it would increase the displacement on the structure's surface and changing the annihilator's height would not produce a significant effect on improving the structure's performance. In addition, the lack of vertical annihilators increases the displacement in the structure.
3.2. In this mode, the length of the upper annihilator is $10 \mathrm{~m}$ and its height up to the tunnel's ceiling is considered in three cases, i.e. 1,2 and $3 \mathrm{~m}$. the results are shown in figures 7 and 8 in order to be compared to cases 5 and 6 shown with vertical annihilators.

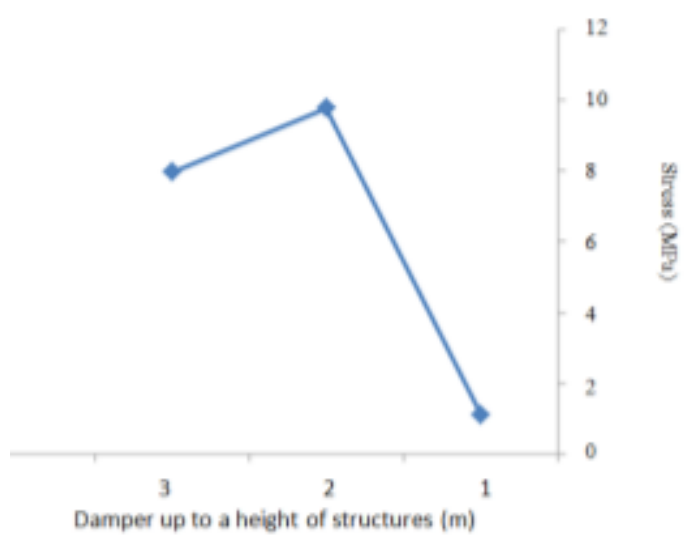

Fig. 5. maximum displacement for the 10-m horizontal annihilator with vertical annihilators

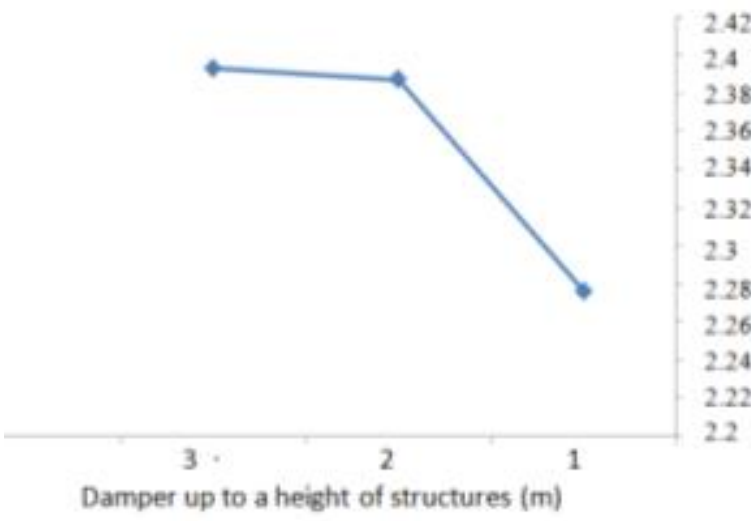

Damper up to a height of structures (m)

Fig. 6. maximum displacement for the 10-m horizontal annihilator with vertical annihilators 


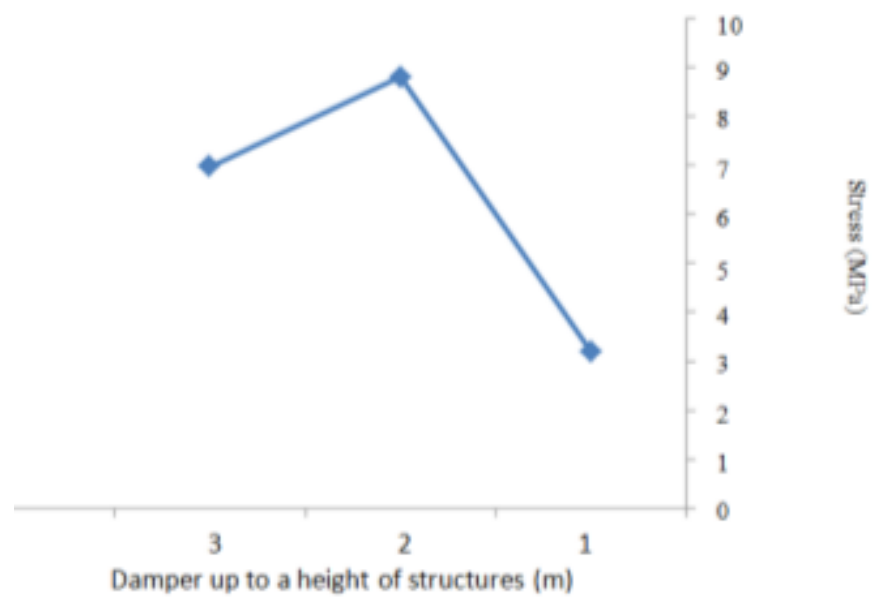

Fig. 7. maximum stress for the 10-m horizontal annihilator without vertical annihilators

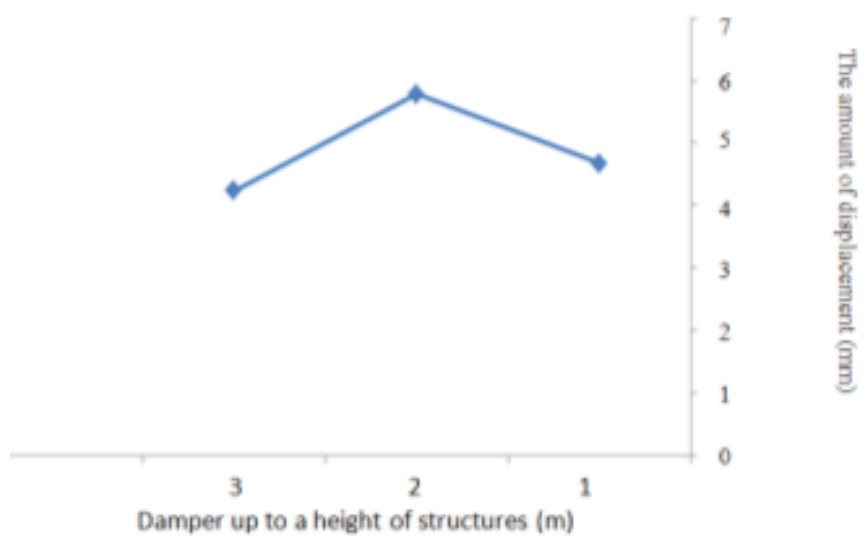

Fig. 8. maximum displacement for the 10-m horizontal annihilator without vertical annihilators

The above figures show that if the annihilator protects the whole structure's surface, it would decrease the displacement on the structure's surface to some extent; however the structure's performance against the effects of stress decreases.

3.3. In this mode, the length of the upper annihilator is $12 \mathrm{~m}$ and its height up to the tunnel's ceiling is considered in three cases, i.e. 1, 2 and $3 \mathrm{~m}$ to obtain the following results shown in figures 9 and 10. In addition, the case without the influence of vertical annihilators is shown in figures 11-12 in order to be compared to cases 9-10 with vertical annihilators. 


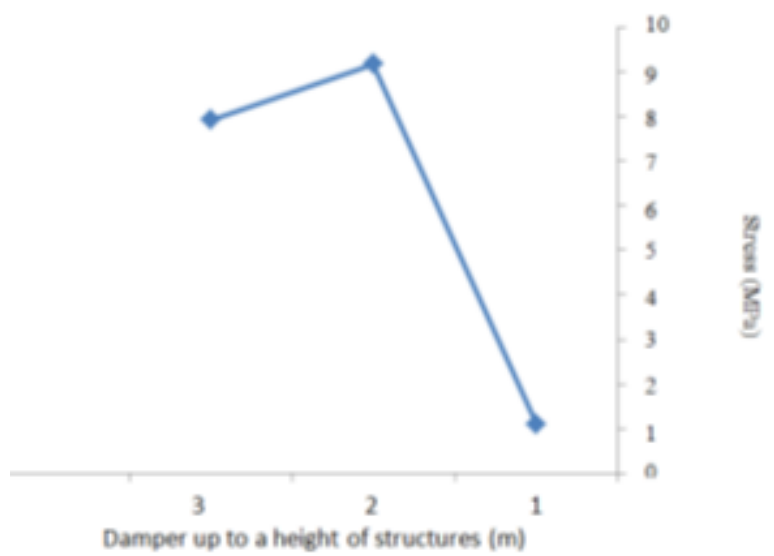

Fig. 9. maximum stress for the 12-m horizontal annihilator with vertical annihilators

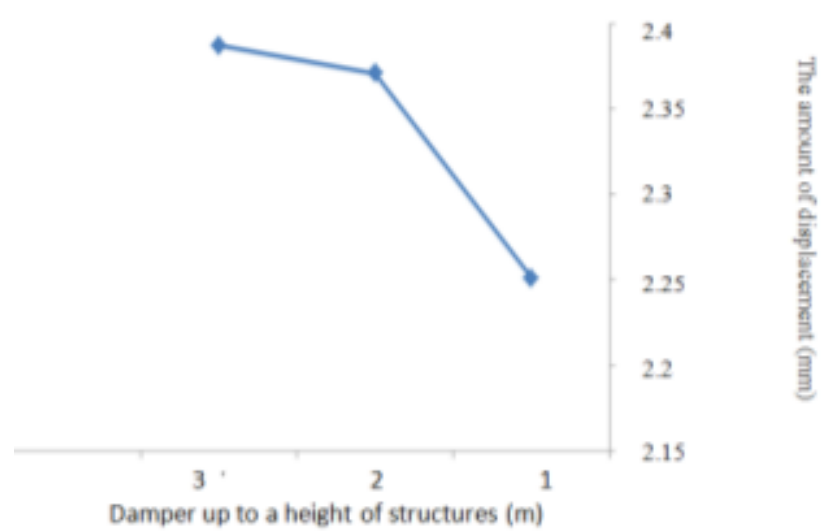

Fig. 10. maximum displacement for the 10-m horizontal annihilator with vertical annihilators

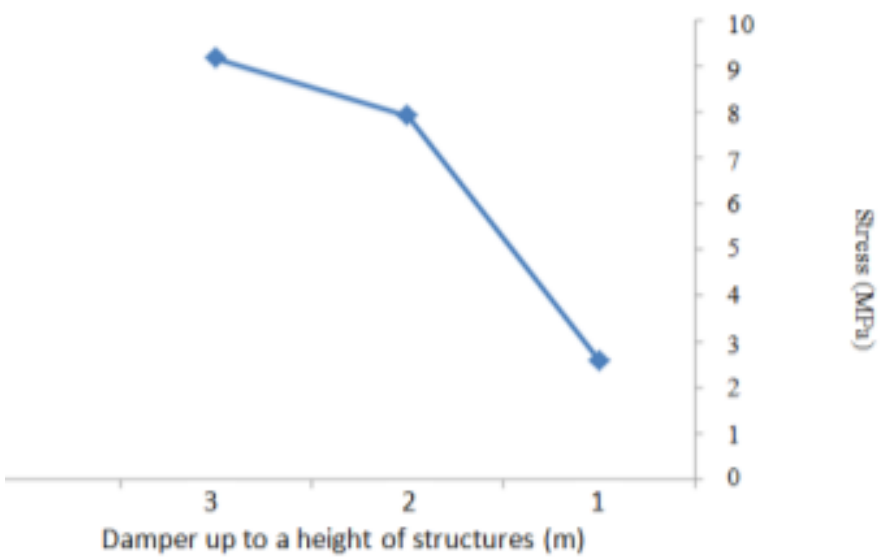

Fig. 11. maximum stress for the 12-m horizontal annihilator without the existence of vertical annihilators 


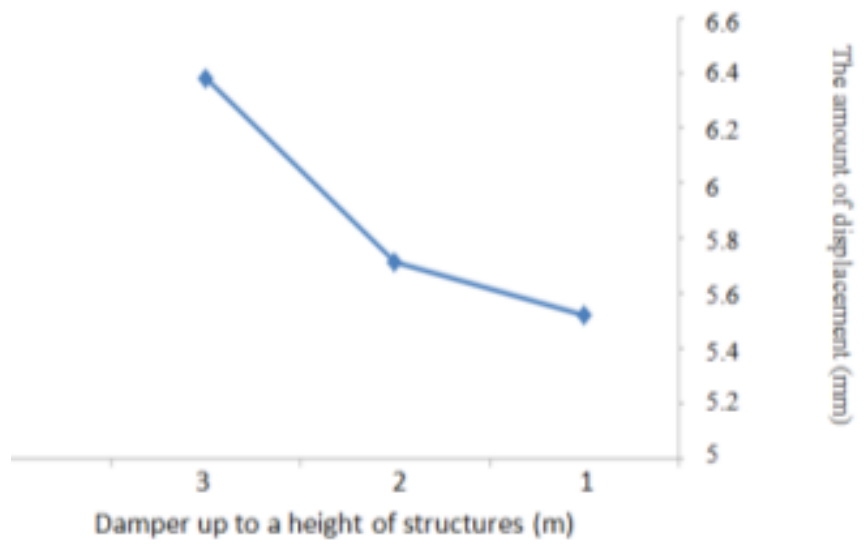

Fig. 12. maximum displacement for the 12-m horizontal annihilator with vertical annihilators

The above figures show that if the annihilator's length is assumed bigger than the tunnel's structure surface, it would decrease displacement on the structure's surface and increases the structure's performance against stress. It is important to mention that the existence of vertical annihilators is very effective on the structure's performance against displacement and stress.
3.4. Overall influence of the vertical annihilator on the maximum displacement In order to have a more precise investigation and better clarification, the displacement effects of the upper annihilators with the influence of vertical annihilators are depicted separately in figure 13.

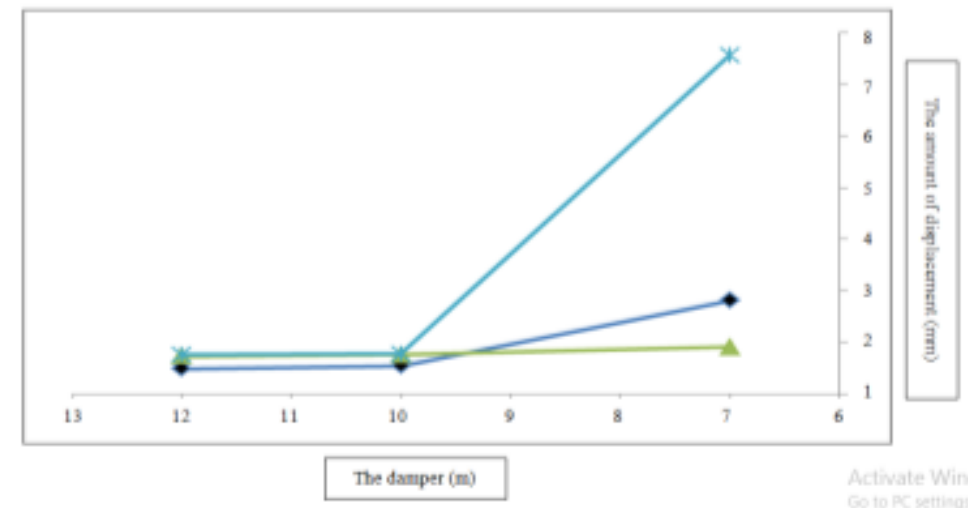

Fig. 13. The overall mode of three annihilators in displacement

According to the results, the upper 12-m annihilator shows a better performance in terms of results analysis. Results indicate that the upper annihilator located $1 \mathrm{~m}$ away 3.5. Extent of maximum displacement without the influence of the vertical annihilator

In order to have a more precise investigation and better clarification, the from the structure's surface, shows a better performance against explosive load. The difference up to 2 and $3 \mathrm{~m}$ is $5.3 \%$ and $6.2 \%$, respectively.

displacement effects of the upper annihilators without the influence of vertical annihilators are depicted separately in figure 14 . 


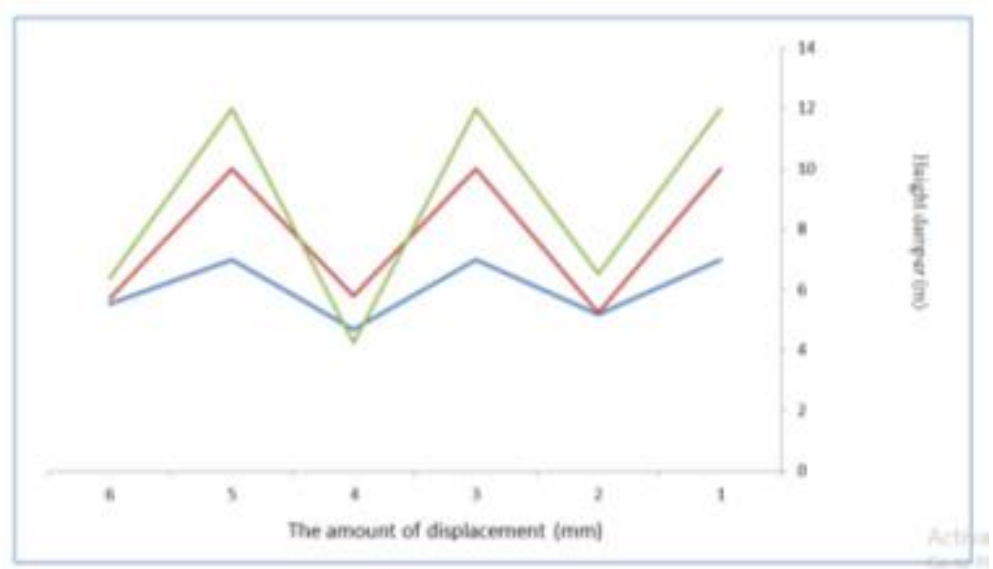

Fig. 14. The overall mode of three annihilators in displacement without the influence of vertical Annihilators

In general, if it is desired to compare the mode without the influence of vertical annihilators to the mode with the influence of vertical annihilators, in the case where the upper $12-\mathrm{m}$ annihilator is $1 \mathrm{~m}$ away from the structure's surface, if vertical annihilators are ignored, there would be a difference as much as almost $145 \%$ from the mode with vertical annihilators.

\section{4- CONCLUSION}

According to the modes considered (14 modes), the following results were obtained for the above-mentioned model:

- Using vertical sinks as annihilators around the structure, decreases the effects of explosion and displacements.

- Among the modes considered for the arrangements of the annihilators, the best mode is where the annihilator is $12-\mathrm{m}$ long, $1 \mathrm{~m}$ under the structure's ceiling.

- The less the annihilator's length, the less its distance to the structure that would damage the structure.

\section{5- REFERENCES}

Lamb, H. (1895) "Hydrodynamics", Cambridge Press.

Baker, J.F., Leader Williams, E. and Lax, P. (1948), "The design of framed buildings against high explosive bombs", The Civil Engineer in War, UK Institution of Civil Engineers, London, p. 80.
Jin Son, Abolhassan Astaneh-Asl, Marcus Rutner, (2005), "Performance of Bridge Decks Subjected to Blast Load", the 6th Japanese-German - Bridge - Symposium, Munich, Germany

Brode, H.L. (1959), "Blast wave from a spherical charge, The Physics of Fluids", 2(2), March/April.

Luccioni B.M., Rougier V.C., (2006), Article "Concrete pavement slab under blast loads", International Journal of Impact Engineering, 1248-1266

Foyouz A., Mojtahed Pour M. and Tavakkoli Zadeh M. (1388), "investigation of the effect of the structure materials and shape on the structure performance against explosion", the 8th international congress of civil engineering, Shiraz University, Ordibehesht, 1388 